\title{
Compensating wage differentials and the labor market re-entry of mothers: Evidence from a factorial survey
}

\author{
Katrin Drasch ${ }^{1} \&$ Martin Abraham ${ }^{2}$
}

\begin{abstract}
Mothers still earn substantially less than women without children; this discrepancy is often referred to as the motherhood wage penalty. This paper examines one possible explanation for this penalty: the willingness to accept lower-paying jobs that have more favorable characteristics that help women reconcile family and work. This idea was formulated based on the theory of compensating wage differentials (CWDs). A factorial survey is used to empirically examine the willingness to accept lower-paying jobs. An online survey comprised 398 women who interrupted employment due to family reasons. The results suggest that mothers are willing to accept lower wages for better job characteristics and that in addition to wages, non-monetary characteristics are also important in shaping the re-entry decision.
\end{abstract}

JEL-Classification: J31, C81, C83, Z13

Keywords: female labor force participation; motherhood wage gap; compensating wage differentials; factorial survey

${ }^{1}$ Corresponding author: Dr. Katrin Drasch, Friedrich Alexander University Erlangen-Nuremberg, Institute for Sociology, Chair for Methods of Empirical Social Research, Kochstr. 4, 91054 Erlangen, Germany; email: katrin.drasch@fau.de

${ }^{2}$ Prof. Dr. Martin Abraham, Friedrich Alexander University Erlangen-Nuremberg, Chair of Sociology and Empirical Social Research - Sociology of the Labour Market, Department of Business and Economics, Findelgasse 7/9, 90402 Nuremberg, Germany; email:

martin.abraham@,fau.de 


\section{INTRODUCTION}

Women with children earn substantially less than men and less than women without children. This gap is referred to as the motherhood wage penalty (for an overview, see Gough \& Noonan 2013). In Germany, empirical results with respect to this gap indicate that mothers earn on average between 18 percent and 24 percent less than women without children (Felfe 2012; Gangl \& Ziefle 2009; Beblo et al. 2009). Several possible explanations for the motherhood wage penalty are proposed in the literature, such as human capital depreciation (Becker 1993), discrimination (Correll et al. 2007) and regional immobility (Fuller 2008).

In this paper, we focus on a mechanism that assumes that mothers self-select into mother-friendly jobs that tend to pay less (Becker 1991; England 1992). Theoretically, this self-selection can be explained by the willingness of mothers to "pay" for certain job characteristics (such as flexible working hours) by accepting job offers with reduced pay. This theory of compensating wage differentials (CWDs) (Rosen 1986) is often discussed as a possible explanation for the gender wage gap. However, empirical evidence about the existence of a CWD mechanism for employed mothers is ambiguous, and no clear picture emerged in the literature thus far. On one hand, empirical evidence against CWDs is found (e.g., Glass \& Camarigg 1992; Kilbourne et al. 1994; Jacobs \& Steinberg 1990; Budig \& England 2001; Glauber 2012; Weeden 2005; Budig \& Hodges 2010). On the other hand, support for CWDs can also be found (e.g., Abendroth et al. 2014; Felfe 2009, 2012; Amuedo-Dorantes \& Kimmel 2008; Villanueva 2007).

One problem with the existing empirical evidence regarding CWDs is the need for information about job opportunities that are not realized. With knowledge of unrealized re-entry behavior, it would be possible to trace the importance of certain job characteristics in the re-entry decision. To consider the types of job characteristics that are important for shaping the re-entry decision, research must also examine non-entry. To our knowledge, no existing studies have examined job opportunities that are not realized. Thus, our main aim in this paper is to investigate whether mothers actually self-select into jobs with certain favorable characteristics. Additionally, if such selection exists, we seek to identify the mechanisms that explain the selection of jobs with motherfriendly characteristics.

The insufficient empirical research on the decision to accept or not realize a job-oppurtunity is mainly due to a lack of adequate data. Existing survey data provide no information on job opportunities that are not realized and instead involve only realized labor market re-entry. This 
article is the first to use a factorial survey design to study the CWD explanation of the motherhood wage gap and enable observation of job opportunities that are not realized. By including these offers, we are able to more accurately study the basis for supply side explanations of the motherhood wage gap. We argue that an appropriate explanation for a mother's labor market participation must consider the possibility that the woman's absence from the labor market is unintended. Otherwise, estimations of the motherhood wage gap will be biased because nonemployment among mothers is not randomly distributed. Given that non-entry is difficult to observe in surveys, other strategies become necessary to address the question of whether mothers select into jobs with more favorable characteristics.

For this selection, we focus on a special group of mothers who interrupted their employment after a child's birth for more than three years. Germany's legislation currently provides 36 months of leave, guaranteeing the right to return to the previous employer. Since women who return within this time receive their previous wage and job conditions, CWD is difficult to observe. However, the majority of mothers interrupt their employment for more than one year and often forfeit their old employment relationship (Drasch 2013). Those mothers are forced to look for a new job, and - contrary to women without children - they will have to reconcile this job with their family situation, since such a long employment break means that the spouse is usually the male breadwinner. If CWD holds at all, it should be especially relevant for this group of women.

In this paper, we experimentally describe job offers for this group and examine the probability that a respondent would accept a hypothetical job offer. Using a factorial survey as an experimental design, we seek to determine what types of job characteristics are important when making the decision to accept or not realize a job offer. This instrument is applied in a study of mothers who have long been absent from paid employment but are in the process of re-entering the labor market. With our factorial survey design, we can more closely examine the decision process itself. More precisely, we confront women who participated in an evaluation project of the German Federal Ministry for Family Affairs, Senior Citizens, Women and Youth (BMFSFJ) and the German Federal Employment Agency (BA) with a number of hypothetical scenarios (vignettes) that contain job offers. Those job offers include a number of selected job characteristics with different conditions. For each of these scenarios, the women must determine the likelihood that they would accept the given job offer. 
By employing this experimental design, we are able to overcome two deficits of the current literature: first, we are able to observe job offers that are not accepted by the respondents, and second, we compare the reaction to job offers with different characteristics - often, women can choose only between very similar job offers. Based on these advantages of our design, we specifically address the following research questions: what jobs are prospective re-entrants willing to accept? More precisely, are some job characteristics more important than others? Do women place CWDs on certain job characteristics? Are there differences between women with different individual characteristics? The results of this research contribute to the more general inquiry on how to facilitate mothers' re-entry into the labor force after a period of inactivity.

This paper is structured as follows: The next section presents selected empirical findings on the characteristics that influence the labor market re-entry of mothers and findings on job characteristics that are important to employees when re-entering the labor market. The third section outlines the theoretical framework, including insights from family economics and CWD theory. Then, hypotheses on the probability of accepting or declining a presented job offer are derived. In the next section, the design of the factorial survey that contains selected job offers is outlined. Subsequently, the analysis strategy and variables are explained. The results of the analyses are presented in the sixth section of the paper. Finally, the findings are summarized and discussed.

\section{Previous Research}

Several researchers have estimated the magnitude of the motherhood wage penalty for Germany. Depending on the circumstances, a wage penalty ranging between 9 percent for mothers who retained their original job and 24 percent for mothers who changed jobs after returning to the labor market is found, with an average of 18 percent for (West) Germany for the birth cohort from 1960 to 1964 (Felfe 2012; Gangl \& Ziefle 2009) . Previous studies (e.g., Budig \& England 2001; England et al. 2016) also find similar results for other countries, such as the US. However, a substantial portion of the motherhood wage gap remains unexplained and cannot be explained by differences in human capital endowment or other factors, such as selection into motherhood (Felfe 2012; Gangl \& Ziefle 2009). In addition to the monetary component as a wage penalty, a non-monetary component of a motherhood penalty in terms of reduced occupational status also exists (Abendroth et al. 2014). 
Research has shown that work-family policies account for some of the cross-national variation in the motherhood wage gap (Abendroth et al. 2014; Budig et al. 2016; Gangl \& Ziefle 2009). The German social security system already provides a variety of job benefits that do not exist in other countries, such as paid sick and vacation time, employment protection, and statutory health and unemployment insurance. Germany offers a variety of legal rights for mothers, including extensive maternity and parental leave and, in most cases, the right to return to the previous employer to buffer the negative wage effects of motherhood. The remaining negative effects may be due to the insufficient childcare system for pre-kindergarten children (Gangl \& Ziefle 2009). This system in total has created lengthy employment interruptions stratified by number of children, education (i.e., shorter interruptions for more educated mothers) and many other factors (e.g., Drasch 2013), thus leading to heterogeneous employment patterns for mothers.

Several sources of the wage penalty for motherhood have been proposed (Budig \& England 2001; Felfe 2012). First, knowledge and skills are not fully transferable over time, and human capital erodes in the course of employment interruptions (Mincer 1974). Thus, women's human capital has depreciated over time as they miss work experience because of family-related employment interruptions (Kunze 2002). Second, there is evidence that employers discriminate against mothers (e.g., Budig \& England 2001; Correll et al. 2007; Paik 2007) and offer them jobs with lower wages because they expect those women to be less productive. Thus, generous family policy provisions have the unintended consequence of creating statistical discrimination against all mothers (Gangl \& Ziefle 2009). Third, women with certain unobservable characteristics (e.g., restricted abilities and preferences for children) self-select into motherhood, which creates unobserved heterogeneity and eventually leads to an overestimation of the motherhood penalty. Fourth, mothers can be expected to be less mobile than non-mothers and therefore have less access to better-paying jobs (e.g., Becker 1991; empirically, see Shihadeh 1991; Boyle 2003). Fifth, children might lead to reduced job effort and productivity. Part-time work can be interpreted as an indicator of reduced job effort. All these sources are well examined in empirical research.

Another possible mechanism that has been examined to a lesser extent is self-selection of mothers into jobs with more favorable non-pecuniary characteristics that lead to sectorial and occupational segregation (Felfe 2012). However, beyond the sectorial and occupational segregation that can be assumed to occur at an earlier stage of an individual's life, mothers' selection of jobs with motherfriendly characteristics can be assumed to occur. In addition, those mother-friendly jobs in turn 
have lower compensation (England \& Budig 2001). This idea is basic to CWD theory, also called the theory of equalizing differences. This theory was originally formulated for labor economics by Sherwin Rosen (1986) and was adapted to sociology most notably by Paula England (1992). According to this theory, the (hourly) wage does not act as a single decision criterion to accept or decline a job offer. Some jobs are more desirable despite their lower pay because they are “interesting, safe, pleasant or otherwise satisfying” (England 1992: 69). This finding is also supported by qualitative literature about mothers' career choices, which shows that women indeed have a strong interest in mother-friendly jobs (Stone 2007). Since such jobs are scarce, it is theoretically assumed that these jobs are performed for wages that are lower than the wages for more burdensome jobs, resulting in a CWD (Rosen 1986; Filer 1985; England 1992). To this end, CWD theory has often been used to address the question of physical disamenities, such as dangerous working conditions (Duncan \& Holmlund 1983). However, the theory also seems useful for addressing other types of working conditions, such as practical or mental working conditions (e.g., Glomb et al. 2004).

However, previous research about CWDs provides rather ambiguous results. On one hand, empirical evidence against CWDs is found (e.g., Glass \& Camarigg 1992; Kilbourne et al. 1994; Jacobs \& Steinberg 1990; Budig \& England 2001; Glauber 2012; Weeden 2005; Budig \& Hodges 2010). On the other hand, support for CWDs can also be found (e.g., Abendroth et al. 2014; Felfe 2009, 2012; Amuedo-Dorantes \& Kimmel 2008; Eberts 1986; Villanueva 2007). For example, Abendroth et al. (2014) find that mothers reduce their working hours and accept a loss in occupational status. Felfe (2012) examine job changes within employers and report that women adjust in several dimensions, e.g., working according to a flexible schedule when changing employer.

Several characteristics are found to have a CWD, e.g., working schedule (Felfe 2009) or health insurance coverage (for the US; Amuedo-Dorantes \& Kimmel 2008). Additionally, Groot (1990) examine labor market re-entry in general and find that the labor contract type, job level, commuting time to and from work and length of working hours significantly affect job acceptance. Flabbi and Moro (2012) find that flexible jobs with the availability of part-time work are more important for more educated workers than for less educated workers.

This review of the literature makes clear that there is no consensus about the existence of CWD for the job choice of mothers. This lack of consensus may be due to three deficits of the existing 
studies: first, CWD is investigated only based on accepted job offers; this may lead to biased results since not all mothers may have the opportunity to choose between different jobs. Second, the results are often based on all women, including those that may have children in the future. However, it is a strong assumption that women are willing to pay for mother-friendly jobs if there is no actual need - after all, they could change jobs after birth. Third, especially in Germany, the rights to return - most often part-time - to the previous employer "conserves" the job conditions before birth; hence, women do not choose between different jobs with different CWDs. By employing a factorial survey about hypothetical job offers for a specific group, i.e., mothers who interrupted employment for more than three years, we overcome these obstacles.

\section{THEORETICAL FRAMEWORK AND HYPOTHESES}

As already discussed, the basic idea of CWD is that employees make a trade-off between wages and other job characteristics. Before we can hypothesize about the nature of this trade-off, we consequently have to establish in which job characteristics our job-searching mothers are interested. Hence, the first five hypotheses focus on the importance of job characteristics. Based on those hypotheses, we address the CWD mechanism in the last two hypotheses.

For the first step, we utilize the notion of Rosen (1986) that investments in human capital are disamenities that are compensated later on by better pay. Thus, the theory of compensating differentials allows straightforwardly including human capital theory. As stated by human capital theory, employees have invested in their education, which in turn determines productivity and wages. To accept a wage below this level is equivalent to experiencing a loss relative to the initial investment. Here, prospect theory (Kahneman \& Tversky 1979; Kahneman et al. 1982; Tversky 1982) also becomes relevant, as people attempt to avoid losses by accepting higher risks - that is,

rejecting the "bad" job offer and searching for an uncertain "better" offer. Thus, we hypothesize as follows:

Hypothesis 1: The higher the wage reduction compared with the wage of the job before the interruption, the lower the likelihood that mothers will accept the job offer.

A second argument derived from human capital theory is based on the depreciation of human capital over time. Lower wages as a result of re-entry may stem from the devaluation of a mother's knowledge during the non-employment phase (Mincer \& Ofek 1982). However, depreciation of human capital can continue even after re-entry into the labor market if one's capabilities are not 
used in the current job. When people accept a job below their qualifications, they not only forego higher wages but also lose additional human capital over time. This reasoning leads to our second assumption:

Hypothesis 2: Mothers are expected to have a lower preference for job offers that are below their level of initial qualification than for job offers requiring the same level of qualification.

Although wages should be an important determinant for accepting jobs, our main reasoning is based on the assumption that non-pecuniary job characteristics are relevant to the decision to accept or decline a job offer (Devine \& Kiefer 1991; Rogerson et al. 2005). Non-pecuniary job characteristics should be especially important for mothers if we assume that childcare is still an important task for these women even after they return to paid work. As argued by various researchers, this argument explains women's preferences for so-called "mother-friendly" jobs.

It can be assumed that taking care of children (especially at younger ages) is time consuming. In addition, time spent caring for children is less flexible than time that spent on other activities because external care periods are fixed and limited (e.g., fixed kindergarten or school hours) and because unexpected time requirements for caring arise (e.g., when a child is ill). Thus, women with children seek "mother-friendly" jobs that are "more compatible with the demands for their home responsibilities" and allow for this temporal flexibility (Becker 1991: 75). For example, one may expect that women with children are less available for work during irregular working hours. Women invest more time and energy in domestic human capital and therefore have less time and energy to invest in market human capital. This tendency also contributes to explaining why women with caring and household duties are expected to receive lower wages than men. In summary, the role of mothers as primary caregivers leads to the following hypothesis about women's preferences for temporal flexibility:

Hypothesis 3: Mothers are expected to have a greater preference for flexible working hours or working hours that can be negotiated with the supervisor than for fixed working hours.

To reconcile job and family, most mothers do not want to work full time. Depending on their household and childcare arrangements, they attempt to realize a certain optimal amount of weekly working hours when re-entering the labor market. However, since working hours for most jobs cannot be negotiated freely, women often need to choose between jobs with working hours that exceed or fall short of their individual preference. As a result of childcare restrictions, mothers have 
more problems increasing their working hours than decreasing them, resulting in less income and contributing to the wage penalty:

Hypothesis 4: Mothers are expected to have a greater preference for working fewer hours than for working more hours as initially planned upon the decision to re-enter the labor market.

Similarly, we assume that mothers are less able to work in jobs that require regular travel activities and to spend time on daily commuting. Business travel, especially when it lasts several days, often requires overnight care arrangements for children. More important, commuting is time consuming and expensive. For example, in the case of a family emergency, the mother needs time to commute back to her place of residence. Therefore, the following hypothesis on commuting can be proposed: Hypothesis 5: The longer the commuting time to the offered job, the lower the likelihood that a mother will prefer that job offer.

Hypotheses 1 to 5 are based on the idea that jobs with certain characteristics are more preferable than jobs without these characteristics. The next step is to determine the extent to which women are willing to "trade" certain characteristics for others. In particular, if women are willing to accept a lower wage to obtain more flexibility, then the willingness to trade certain characteristics would contribute to the observed gender gap in wages. This basic idea is behind CWD theory. To address whether CWDs are present in our study, we assume that in addition to wages, other characteristics also play roles in the decision to accept a job offer and that mothers accept reduced wages in exchange for more suitable job characteristics. More precisely, we propose the following:

Hypothesis 6: Mothers accept reduced wages for preferred job characteristics, such as less commuting time and more temporal flexibility in their jobs.

For our last hypothesis, we consider that people differ in their individual pressure to find reemployment. First, for mothers with a higher family income, re-entering the labor market immediately may be less important. Those mothers can more carefully select a job offer. Second, a wage reduction might be less important for mothers whose partner earns a sufficient wage than for single mothers who need the income to support their family. Third, mothers who are already registered as unemployed or are actively searching for work may find it more urgent to re-enter the labor market than do non-registered mothers. Therefore, women who are under higher pressure to find a job may react differently to job offers and may be less reluctant to accept negative job characteristics. Thus, the elasticities of women under pressure and women not under pressure are 
expected to differ. However, the wage offer must be sufficiently high to ensure family security. In summary, one can derive the following hypothesis:

Hypothesis 7: The influence of negative job characteristics, such as reduced wages, overqualification or commuting time, on preferences for accepting a job offer are expected to be less for mothers under pressure to find a job than for mothers not under pressure.

\section{DATA AND METHODS}

\subsection{Factorial survey data}

In the empirical part of our study, we aim to test our hypotheses using an experimental factorial survey design (for a general introduction, see Auspurg \& Hinz 2015; for an overview of empirical studies, see Wallander 2009). In a factorial survey, respondents receive a number of different hypothetical scenarios or vignettes. For each scenario, the respondent is asked to provide a decision. The factorial survey design enables us to disentangle the causal influence of the independent variation of a limited number of dimensions (characteristics) on the decision-making behavior of individuals. Therefore, the vignettes share a basic situation and an assessment scale, but the characteristics of the vignette dimensions differ. Vignettes are also suitable for examining decision-making behaviors in complex situations and facilitate a systematic evaluation of the effects of contextual conditions that are difficult to test in reality.

The application of a factorial survey instead of a standard approach using longitudinal data, for example, has the following advantages: First, the supply side of the job acceptance process is completely controlled. Irrespective of their personal characteristics, all respondents receive the same number of job offers and can express their job preferences. This approach facilitates the observation of unbiased preferences that are not based on a selective sample of mothers who have re-entered the labor market successfully. Second, less attractive job offers can be studied, leading to a more complete picture of the labor market re-entry of mothers. Third, a factorial survey is an ideal way to determine the relative importance of influential factors because respondents cannot state that all job characteristics are equally important, as is often the case in conventional surveys. The factorial survey presented in this paper was implemented in an evaluation project by the Institute for Employment Research (IAB). It was conducted as an online supplement to a telephone survey (CATI). ${ }^{3}$ The study evaluates a joint model project ("Perspektive Wiedereinstieg”) of the

\footnotetext{
${ }^{3}$ The project (excluding the factorial survey) was financed by the Federal Ministry for Family Affairs, Senior Citizens, Women and Youth (BMFSFJ). More information can be found at http://www.bmfsfj.de/BMFSFJ/gleichstellung,did=120704.html [date: 2018-01-25]
} 
Bundesministerium für Familie, Senioren, Frauen and Jugend (BMFSFJ) and the German Federal Employment Service. To participate in the model project, applicants needed to have interrupted paid employment due to family reasons for at least three years. In addition to the project participants, a comparison group of mothers not participating in the model project was also interviewed. Those women were registered at the as unemployed or actively searching for work. The comparison group was generated with a two-stage matching procedure (Diener et al. 2013). Thus, the re-entrants under study constitute a homogenous group.

Data were collected at two different points in time. In the telephone surveys, 1754 women were interviewed in two waves. Among those women, 68.4 percent (1167 persons) gave their consent to participate in the online supplement; thus, those women constitute a convenience sample. A convenience sample is sufficient for this study because we use an experimental method for both the telephone survey and the online supplement. The online factorial survey can also be classified as an experimental method because of the assignment of a random set of vignettes to the respondents. 398 women participated in the factorial survey.

For the factorial survey design, we were able to build on a number of studies that examined the job acceptance of various groups by employing vignettes (cf. Abraham et al. 2013; Auspurg \& Gundert 2015; Bähr and Abraham 2016; for a general introduction to the method, see Auspurg \& Hinz 2015). The vignette dimensions for prospective job re-entrants were selected according to the current state of the research and exploratory conversations with female re-entrants and selected experts on this topic. For the selection, it was also important that the dimensions were universally valid, i.e., that the dimensions most likely apply to any of the re-entrants. Therefore, for example, we did not vary the child's age or the availability of childcare facilities. Furthermore, because the job characteristics needed to be observable without great effort, characteristics such as working atmosphere were excluded. Figure 1 presents a sample vignette and the response scale. The characteristics that vary are displayed in bold. The full set of vignette dimensions is presented in Table 1.4

\footnotetext{
${ }^{4}$ This is an English translation of a sample vignette; originally, the vignettes were written in German.
} 


\section{Figure 1 Sample vignette}

You have just started to look for a job and now receive the first offer. You have no open applications left. You are clearly over-qualified for this job. The working hours do not meet your requirements. You could only work less than you originally planned. Commuting to your new job would take $\mathbf{4 5}$ minutes one way. Your net salary is about 10 per cent less than the one you received before you interrupted your employment career. Your new job has fixed working times that were scheduled beforehand.

How likely is it that you are going to accept the job-offer?

$0 \%-100 \%$

\begin{tabular}{|c|c|c|c|c|c|c|c|c|c|c|}
\hline 0 & 10 & 20 & 30 & 40 & 50 & 60 & 70 & 80 & 90 & 100 \\
\hline$\Gamma$ & T & $T$ & $T$ & $T$ & & $T$ & $T$ & 1 & $T$ & ד \\
\hline
\end{tabular}

Table 1 Dimensions and levels used in the vignette study

\begin{tabular}{ll}
\hline Vignette dimension & Vignette levels \\
\hline wage & 1 according to previous job \\
& 210 per cent less \\
training & 330 per cent less \\
& 1 according to training/abilities \\
& 2 slightly over qualified \\
working hours & 3 clearly over qualified \\
& 1 flexible \\
volume of work & 2 agreed upon with supervisor \\
& 3 fixed \\
commuting time & 1 according to wishes \\
& 2 more than planned \\
& 3 less than planned \\
search effort & 115 minutes \\
situation & 230 minutes \\
& 345 minutes \\
& 1 already searching for some time \\
\hline
\end{tabular}




\subsection{Methodological aspects of the factorial survey and analysis strategy}

For constructing our factorial survey, we employ a quota selection according to the D-efficiency criterion of the vignette universe ( $\mathrm{N}=972$ ), which consists of all possible combinations of the seven varying dimensions (Auspurg \& Hinz 2015; Dülmer 2007, 2016). ${ }^{5}$ Ten vignettes were presented to each respondent in random order. In total, 20 different vignette decks were created. For small samples, this quota sampling is superior to the random selection and allocation of vignettes to individuals. This approach is based on a systematic compilation of vignettes with the explicit goal of covering all possible combinations equally (Dülmer 2007, 2016). ${ }^{6}$

A multilevel structure is present in the data because every respondent provides an answer to more than one vignette. Using OLS regression would lead to reduced standard errors resulting in too high p-values and thus a possible overestimation of the significance of the coefficients. We correct the bias resulting from this cluster data by using multilevel modelling. Thus, we first estimate a random intercept model and include a respondent-specific intercept in the analyses. This intercept contains the time-constant effects of personal characteristics that cannot be included in the model (Rabe-Hesketh \& Skrondal 2012; Auspurg \& Hinz 2015, 89 ff.). The model can be formulated as follows:

$$
Y_{i j}=\beta_{0}+\beta X_{i j}+\gamma Z_{j}+\sigma, Z_{j} X_{i j}+\mu_{j}+\varepsilon_{i j}
$$

where $Y_{i j}$ denotes the vignette judgment; $\beta_{0}$ is the intercept; $X_{i j}$ is the set of variables on the vignette level; $Z_{j}$ denotes the variables on the individual level, $Z_{j} X_{i j}$ denotes the possible interactions between the individual and the vignette level; $\mu_{\mathrm{j}}$ is the time-constant individual specific error term; and $\varepsilon_{i j}$ denotes the remaining error term. The betas $\beta$ are the effect coefficients on the vignette level, the gammas the effect coefficients on the respondent level $\gamma$ and the sigmas $\sigma$ the interaction effects. Subsequently, it becomes necessary to test for the presence of random coefficients, thus varying the effects for different respondents (Rabe-Hesketh \& Skrondal 2012: $181 \mathrm{ff}$.). Furthermore, to test predictions of CWD, we expand our basic multilevel regression model by including interactions of

\footnotetext{
${ }^{5}$ From the vignette universe, 200 vignettes were selected. The dimensions of those vignettes are largely uncorrelated, and the variation in the dimensions and, thus, the D-efficiency reaches a maximum. In our case, we obtained a value of 98.1, with 100 being the maximum. This orthogonalization considers all main effects and first-order interactions that denote a Resolution V Design (Dülmer 2007, 2016; Kuhfeld et al. 1994; Kuhfeld 2010). The vignette selection was performed with SAS and the macros \%mktex and \%mktblock. This strategy was proposed by Kuhfeld (2010). We thank Katrin Auspurg, LMU Munich, for the technical implementation.

${ }^{6}$ Steiner and Atzmüller (2006) provide a concise overview of various strategies used to select vignettes and build the vignette decks. In addition, they provide information about the statistical analysis techniques used to interpret the results.
} 
all vignette dimensions that reflect the job conditions and use this model to estimate linear predictions of selected vignette scenarios. The selection is based on the availability of suitable comparisons because those are limited due to the D-efficient design. In addition, we test whether the interaction coefficients of the two different scenarios are significantly different from each other. The dependent variable denotes the probability of accepting the given job offer and ranges from zero percent to 100 percent with intermediate steps of five percent. We will treat this as a metric variable. ${ }^{7}$ We assign seven dimensions that describe the job offer. The monetary characteristics of the job offer are modelled with different amounts of wage loss compared with the previous job. The commuting time to and from work is varied to include monetary incentives for transport costs and non-monetary incentives, such as stress and time. Non-monetary characteristics are modelled by the level of qualification needed for the proposed job compared to the qualification originally obtained. Characteristics related to temporal flexibility include the flexibility of working hours and the desired volume of work. In addition, because the duration of the search process and the number of job offers received are crucial for the decision to accept or decline a job offer, these characteristics are additionally controlled for in the factorial survey. Thus, on the vignette level, we control for whether the woman has just begun her search or has already been searching for some time. Another variable controls for pending applications of the respondent.

Characteristics on the individual level include the employment status of the partner, whether children under six are present in the household, the age of the respondent, whether she is under pressure to find a job (e.g., because she is unemployed or a single parent), the duration of the interruption and whether the woman holds a tertiary degree as a measure of human capital. Furthermore, we account for whether the woman lives in the new (former GDR before German reunification in 1990) or old (FRG before 1990) federal states. Additionally, we control for whether a woman participated in the model project and whether she was included in the subsample of registered employment re-entrants. Table 2 presents summary statistics regarding the dependent variable and variables on the individual level.

\footnotetext{
${ }^{7}$ Auspurg and Gundert (2015) show with a similar design indicating that the results from more complicated models, such as hurdle models, are essentially the same.
} 
Table 2 Descriptive statistics

\begin{tabular}{llllll}
\hline Variable & mean & sd & min & max & N \\
\hline vignette judgement $(0-100$ per cent) & 63.64 & 28.88 & 1 & 100 & 398 \\
partner fulltime employed (1=yes) & 0.77 & & 0 & 1 & 398 \\
child under 6 in household (1=yes) & 0.18 & & 0 & 1 & 398 \\
under pressure to find a job (1=yes) & 0.44 & & 0 & 1 & 398 \\
age (in years) & 42.01 & 6.39 & 25 & 60 & 398 \\
living in new federal state(1=yes) & 0.19 & & 0 & 1 & 398 \\
tertiary education (1=yes) & 0.42 & & 0 & 1 & 398 \\
duration of interruption (in years) & 11 & 6.5 & 0 & 30 & 398 \\
cohort (1= first cohort) & 0.59 & & 0 & 1 & 398 \\
participant vs comparison group (1=Participant) & 0.48 & & 0 & 1 & 398 \\
\hline
\end{tabular}

Furthermore, we are interested in modelling the relative importance of the variable dimension. To achieve this goal, we can use the properties of the factorial survey: uncorrelated main effects and first-order interactions. When independent variables are mutually uncorrelated, decomposition of $\mathrm{R}^{2}$ is possible, and the importance of a variable is often determined from its contribution to $\mathrm{R}^{2}$. A similar approach is used when estimating the contribution to explained variance. The influence of one dimension can be estimated by calculating the ratio of explained variance to overall variance (Berk 2004: 117; Bring 1994). In addition, the question of relative importance can be addressed by calculating (semi-)partial correlations. For the given properties, one can also directly examine the t-values of the parameters (Bring 1994), the sizes of the parameters or the bivariate correlations between the parameters and the dependent variables. In this paper, we mainly interpret the proportion of explained variance relative to the total explained variance on the vignette level because these values conveniently sum to 100 percent. Additionally, we present the significance levels of the partial correlations that lead to similar conclusions as the explained variance. 


\section{RESULTS}

\subsection{Descriptive results}

Our dependent variable is a woman's likelihood of accepting a given job offer as evaluated by the respondent. The acceptance scale ranged from 0 percent to 100 percent. ${ }^{8}$ The slider was originally set to 0 to ensure that respondents had to move the slider to a different value. Figure 2 presents the distribution of the dependent variable.

\section{Figure 2 Distribution of the vignette judgments}

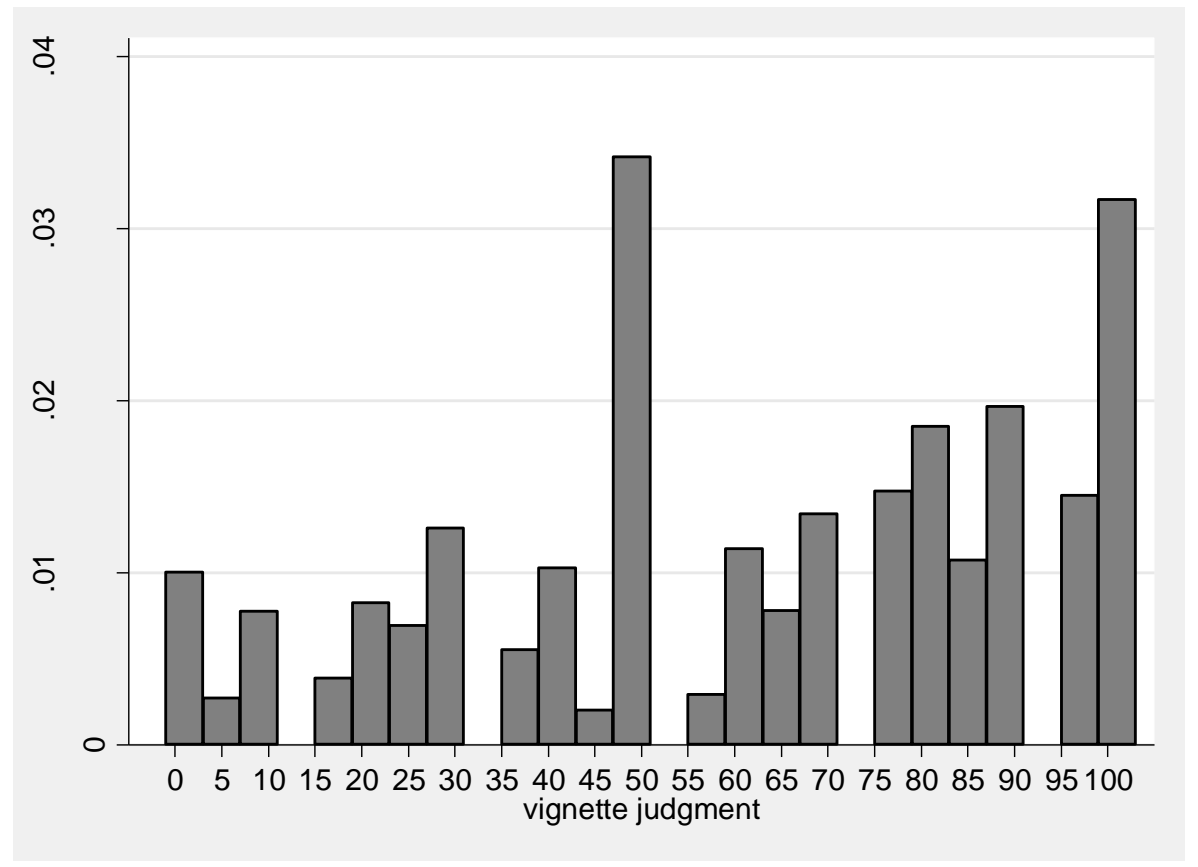

The acceptance rate for job offers is high and often varies between 80 percent and 100 percent. One peak is visible at 50 percent, indicating that some women have made inconclusive judgements about the presented job offer. The other peak is visible at 100 percent, indicating that some women were absolutely positive about accepting this job offer. However, approximately 30 percent of the judgements denoted an acceptance probability of less than 50 percent, indicating variability among the vignette dimensions and, thus, in re-entry intention.

\footnotetext{
${ }^{8}$ The variable is unevenly distributed, and thus, we instead used an 11-point scale. The results are robust to different specifications of the dependent variable. Although the variable itself is not normally distributed, the standardized level1 residuals appear normal and do not violate the assumption of normal sampling distributions of the residuals (see Rabe-Hesketh \& Skrondal 2012: 160 ff.). The results are available upon request.
} 


\subsection{Model specification}

The results of our multilevel model are also presented in Table $3 .{ }^{9}$ In Model 1, we included the vignette characteristics, and in Model 2, we included the individual characteristics. Finally, we sought to determine whether respondents from the participation and comparison groups judged the vignettes similarly. The results of a Hausman test (see Rabe-Hesketh \& Skrondal 2012: 157) reveal homogenous error variance on the vignette level; thus, all respondents follow a similar strategy. This result is not surprising because the sample consists of a rather homogenous group of women. ${ }^{10}$ In summary, estimation with random intercept models seems to be the appropriate strategy for our purpose.

\subsection{Test of hypotheses}

Model 2 in Table 3 presents the results of the final random intercept model controlling for individual characteristics. Coefficients with a negative sign indicate a lower probability of reentering the labor market as the independent variable increases, while a positive sign indicates a higher probability.

\footnotetext{
${ }^{9}$ First, we address the question of whether a multilevel modelling strategy is indeed necessary. To answer this question, we performed a likelihood ratio test of the empty multilevel model against a linear regression, a Lagrange-Multiplier test (Rabe-Hesketh \& Skrondal 2008: 92) and an F-test searching for unexplained between-cluster heterogeneity, as proposed by Wooldridge (2002). Those tests revealed that the multilevel approach is necessary and that a mere clustering of the observations and calculation of robust standard errors would not be sufficient and would lead to biased results.

${ }^{10}$ The results are available upon request.
} 
Table 3 Random intercept models for women, empty model, vignette model and full model

\begin{tabular}{|c|c|c|c|}
\hline Dependent variable vignette judgment & Hypothesis & $\begin{array}{c}\text { Model 1 } \\
\text { vignette } \\
\text { characteristic }\end{array}$ & $\begin{array}{c}\text { Model } 2 \\
\text { +individual } \\
\text { characteristics }\end{array}$ \\
\hline (0-100 per cent) & & $\mathbf{S}$ & \\
\hline
\end{tabular}

vignette level variables

wage: ref. according to previous job

wage: 10 per cent less

wage: 30 per cent less

training: ref. according to training/abilities

training: slightly over qualified

training: clearly over qualified

working hours: ref. flexible

working hours: agreed upon with supervisor

working hours: fixed

volume of work: ref. according to wishes

volume of work: more than planned

volume of work: less than planned

commuting time: ref. 15 minutes

commuting time: 30 minutes

commuting time: 45 minutes

search effort: ref. already searching for some

time

search effort: just started

situation: ref. some applications left

situation: no open applications left

individual level variables

under pressure ref. not under pressure

tertiary education ref. no

H5

H1

$\mathrm{H} 2$

$\begin{array}{cc}-5.19^{* * *} & -5.11^{* * *} \\ (0.78) & (0.78) \\ -18.4^{* * *} & -18.40^{* * *} \\ (0.78) & (0.78)\end{array}$

$\begin{array}{lc}-3.42^{* * *} & -3.42^{* * *} \\ (0.78) & (0.78) \\ -8.75^{* * *} & -8.74^{* * *} \\ (0.78) & (0.78)\end{array}$

$\mathrm{H} 3$

H4

$\begin{array}{cc}-1.76^{*} & -1.75^{*} \\ (0.78) & (0.78) \\ -8.73^{* * *} & -8.72^{* * *} \\ (0.78) & (0.78)\end{array}$

$\begin{array}{cc}-15.37^{* * *} & 15.37^{* * *} \\ (0.78) & (0.78) \\ -6.69^{* * *} & -6.69^{* * *} \\ (0.78) & (0.78)\end{array}$

$-7.54^{* * *} \quad-7.54^{* * *}$

(0.78) (0.78)

$-22.41^{* * *} \quad-22.40^{* * *}$

(0.78) (0.77)

$-0.64 \quad-0.64$

(0.63) (0.63)

$2.21^{* * *} \quad 2.21^{* * *}$

(0.64) (0.63)

$4.16^{*}$

(1.88)

$4.32^{*}$

(1.79)

$4.10^{*}$

(1.74)

2.78

(2.24)

1.10

(2.61)

0.17

$(0.18)$

$-0.07$

$(0.19)$

2.79

(2.35)

living in new federal state ref. old federal states 
participation group ref. comparison group

\begin{tabular}{lcc} 
constant & & $(1.76)$ \\
& $93.97^{* * *}$ & $86.64^{* * *}$ \\
\hline random intercept standard deviation & $(1.43)$ & $(7.53)$ \\
level 1 residual standard deviation & 16.65 & 16.55 \\
\hline rho & 19.83 & 19.76 \\
chi2 & 0.413 & 0.412 \\
individuals & 2116.77 & 2149.43 \\
observations & 395 & 395 \\
\hline Ranvation & 3925 & 3925 \\
\hline
\end{tabular}

Random intercept models; standard errors in parentheses

${ }^{*} p<0.05,{ }^{* *} p<0.01,{ }^{* * *} p<0.001$, two-tailed tests

First, we test hypothesis 1 . The effect of the wage loss is highly significant and is in the expected direction. An anticipated wage loss of 10 percent reduces the probability of re-entry by approximately 5 percentage points; a 30 percent wage loss drastically decreases the re-entry probability by 18 percentage points. Thus, we can confirm hypothesis 1: the higher the wage reduction compared with the wage of the job held prior to the interruption, the lower the preference for accepting the job offer.

Considering the relevance of the other non-monetary characteristics and testing hypothesis 2, we observe the following results: receiving an offer for a job for which one is clearly overqualified rather than an offer for a job that is in accordance with one's training and abilities decreases the reentry probability by approximately 9 percentage points. A job offer for which one is only slightly overqualified decreases the acceptance probability significantly, by approximately 3 percentage points. Therefore, we find support for hypothesis 2 with respect to the level of qualification. Mothers have a significantly lower preference for jobs that are below their level of initial qualification.

We then test hypotheses 3 and 4, which examine characteristics related to temporal flexibility. Compared to flexible working hours, fixed working hours decrease the re-entry probability by 9 percentage points, while working hours agreed upon with the direct supervisor decrease this probability by 2 percentage points. Related to hypothesis 4 , a job offer that includes more working hours than originally planned decreases the re-entry probability by 15 percentage points relative to a job offer containing as many hours as originally planned. Additionally, having fewer working hours than planned decreases the re-entry probability by 7 percentage points. Both of the effects related to temporal flexibility are highly significant. In summary, we find support for hypotheses 3 and 4 . Both the volume of work and the flexibility of working hours have a significant influence on job offer acceptance. 
Concerning hypothesis 5 , we find that a commuting time of 30 minutes decreases the re-entry probability by 22 percentage points relative to a commuting time of 15 minutes; a commuting time of 45 minutes decreases this probability by 7 percentage points. This value is the highest for all the dimensions under study. Thus, hypothesis 5 can also be confirmed: a longer commuting time decreases job acceptance preferences.

Considering the control variables on the individual level, we find the following results: Compared to women who are not under pressure to find a job, women under pressure are more likely to accept a job offer. This result is in accordance with our general expectations that women who have registered as unemployed or have a low family income are less reluctant to accept a job offer. Additionally, holding a tertiary education degree generally increases the re-entry probability. This result is consistent with the findings of previous research from life course studies (e.g., Aisenbrey, Evertsson, and Grunow 2009) and assumptions from human capital theory that highly educated women intend shorter periods of interruption. Furthermore, women from the first cohort have a significantly higher re-entry probability than women from the second cohort because women from the first and second cohort are recruited from the same geographical areas; thus, women with a greater need for employment may be expected to participate in the program earlier. For the comparison group, this result can ultimately be explained by the improved economic situation in 2011 compared with 2010. Surprisingly, the employment status of the partner, the presence of a child under the age of 6 in the household and the duration of the interruption are not relevant factors, probably because of the homogenous group under study. Most respondents have a partner but no children below the age of 6 years in the household and have been inactive on the labor market for several years. Additionally, no age effect could be detected. Finally, living in the new federal states and belonging to the comparison group are not relevant factors. Therefore, despite the persistence of large differences among females, especially in mothers' labor force participation (Cohany \& Sok 2007; Hanel \& Riphan 2012), women from the old and new federal states have similar attitudes toward relevant job characteristics.

Hypothesis 6 addresses the question of the presence of a CWD for the group under study. Theoretically, this hypothesis means that the direct monetary compensation for the offered job has a significant positive influence, but other non-monetary characteristics must also be relevant; in particular, positive characteristics should positively influence the re-entry probability (Kilbourne et al. 1994). In our study, we find a highly significant influence of the most direct monetary measure 
of job characteristics, financial compensation for work, but also a highly significant influence of almost all other characteristics involving non-monetary aspects of the financial compensation.

In summary, we find support for hypothesis 6, which indicates that in addition to wages, other characteristics play a role in the decision to accept a job offer and that mothers accept reduced wages in return for preferred job characteristics. Our results show that if women are offered flexible working hours, they tend to accept lower wages. The notion of CWDs indeed seems relevant for women with family-related employment interruptions. These findings are in contrast to empirical results based on survey data: for example, Glauber (2012) finds no evidence for compensating mechanisms concerning workplace flexibility in the US (similar to Weeden 2005), and McCrate (2005) finds only small effects. However, these discrepancies may arise because only realized matches can be observed in surveys. McCrate (2005) states that women generally do not have more flexible working arrangements. Consequently, mothers seeking re-entry may choose not to be employed or choose to be employed with fewer working hours. 
Table 4 Likelihood of job acceptance for different settings

\begin{tabular}{|c|c|c|c|c|c|}
\hline \multicolumn{5}{|c|}{ Interaction effect } & $\begin{array}{l}\text { Predicted } \\
\text { likelihood of } \\
\text { job acceptance }\end{array}$ \\
\hline \multicolumn{5}{|c|}{ Highest job acceptance probability in sample } & \\
\hline $\begin{array}{l}\text { Wage } 10 \text { per } \\
\text { cent less }\end{array}$ & Slightly over qualified & $\begin{array}{l}\text { Working hours } \\
\text { agreed upon } \\
\text { with } \\
\text { supervisor }\end{array}$ & $\begin{array}{l}\text { Working } \\
\text { hours } \\
\text { according to } \\
\text { wishes }\end{array}$ & $\begin{array}{l}\text { Commuting time } \\
15 \text { minutes }\end{array}$ & $\begin{array}{l}95.90 \\
(5.96)\end{array}$ \\
\hline \multicolumn{6}{|c|}{$2^{\text {nd }}$ highest job acceptance probability in sample } \\
\hline $\begin{array}{l}\text { According to } \\
\text { previous job }\end{array}$ & Clearly overqualified & $\begin{array}{l}\text { Working hours } \\
\text { agreed upon } \\
\text { with } \\
\text { supervisor }\end{array}$ & $\begin{array}{l}\text { Working } \\
\text { hours } \\
\text { according to } \\
\text { wishes }\end{array}$ & $\begin{array}{l}\text { Commuting time } \\
15 \text { minutes }\end{array}$ & $\begin{array}{l}94.77 \\
(3.57)\end{array}$ \\
\hline \multicolumn{6}{|c|}{ Lowest job acceptance probability in sample } \\
\hline $\begin{array}{l}\text { Wage } 30 \text { per } \\
\text { cent less }\end{array}$ & $\begin{array}{ll}\text { According } & \text { to } \\
\text { training/abilities } & \end{array}$ & Fixed & $\begin{array}{l}\text { Working } \\
\text { hours } \\
\text { according to } \\
\text { wishes }\end{array}$ & $\begin{array}{l}\text { Commuting time } \\
45 \text { minutes }\end{array}$ & $\begin{array}{l}25.87 \\
(4.23)\end{array}$ \\
\hline \multicolumn{6}{|c|}{$2^{\text {nd }}$ lowest job acceptance probability in sample } \\
\hline $\begin{array}{l}\text { Wage } 30 \text { per } \\
\text { cent less }\end{array}$ & Slightly over qualified & Fixed & $\begin{array}{l}\text { More hours } \\
\text { than planned }\end{array}$ & $\begin{array}{l}\text { Commuting time } \\
45 \text { minutes }\end{array}$ & $\begin{array}{l}28.23 \\
(4.98)\end{array}$ \\
\hline
\end{tabular}




\begin{tabular}{|c|c|c|c|c|c|c|}
\hline \multicolumn{5}{|c|}{ (H6) Reduced wages for preferred job characteristics } & $\begin{array}{l}\text { Predicted } \\
\text { likelihood of } \\
\text { job } \\
\text { acceptance }\end{array}$ & $\begin{array}{l}\text { Difference of } \\
\text { coefficients } \\
\text { (p-values) }\end{array}$ \\
\hline \multicolumn{7}{|c|}{$\begin{array}{l}\text { Scenario with no wage reduction but less-preferred non-monetary job } \\
\text { characteristics }\end{array}$} \\
\hline $\begin{array}{l}\text { According } \\
\text { to previous } \\
\text { job }\end{array}$ & $\begin{array}{l}\text { Clearly } \\
\text { overqualified }\end{array}$ & Fixed & $\begin{array}{l}\text { Working } \\
\text { hours less } \\
\text { than } \\
\text { planned }\end{array}$ & $\begin{array}{l}\text { Commuting } \\
\text { time } 45 \\
\text { minutes }\end{array}$ & 55.60 & $0.009 * *$ \\
\hline \multicolumn{7}{|c|}{$\begin{array}{l}\text { Scenario with } 30 \text { per cent reduction but preferred non-monetary job } \\
\text { characteristics }\end{array}$} \\
\hline $\begin{array}{l}\text { Wage } 30 \text { per } \\
\text { cent less }\end{array}$ & $\begin{array}{l}\text { According to } \\
\text { training/abilities }\end{array}$ & Flexible & $\begin{array}{l}\text { Working } \\
\text { hours } \\
\text { according } \\
\text { to wishes }\end{array}$ & $\begin{array}{l}\text { Commuting } \\
\text { time } 15 \\
\text { minutes }\end{array}$ & 77.86 & \\
\hline
\end{tabular}

Predictions obtained from a random intercept model including interaction effects of the vignette dimensions wage, training, working hours, volume of work, and commuting time; no individual controls due to parsimony of the model. Standard errors are quoted in parentheses. Difference tested with a linear test of coefficients, ${ }^{*} \mathrm{p}<0.05$, $* * \mathrm{p}<0.01, * * \mathrm{p}<0.001$

In Table 4, we also compare the job acceptance probabilities of selected scenarios to test hypothesis 6 more thoroughly. First, we conclude that the two scenarios with the highest job acceptance contain similar mother-friendly characteristics, although the scenario with the highest job acceptance probability is also connected with a 10 percent decrease in wages. Regarding the lowest job acceptance probability, the scenarios contain characteristics that are generally seen as less favorable, such as a 45 -minute commuting time, and they are also connected to a 30 percent wage decrease. Only with respect to required training is no clear pattern can be detected. Additionally, working hours seem to be less important. To test hypothesis 6 directly, we compare a scenario with no wage reduction but less-preferred non-monetary job characteristics with a scenario with 30 percent reduction but preferred non-monetary job characteristics. The scenario including no wage reductions leads to an average job acceptance probability of approximately 55 percent, compared 
to 78 percent in the scenario with a high wage loss but favorable job characteristics. The linear predictions derived from these coefficients also differ significantly from each other $(p<0.01)$. To summarize, we find additional support for hypothesis 6 .

With respect to the control vignette characteristics, the results in Table 2 show that for the respondents in our study, search effort has no influence on the re-entry decision. Additionally, the relative importance of this dimension is rather low and explains little of the total variance. This finding can be attributed to the specific situations of the participating women. Those women have often been inactive in the labor market for several years, and additional search time is no longer important. This dimension might be more important for a different group under study, such as unemployment benefit recipients. However, we find that the availability of job offers influences the acceptance rate. In a situation where the re-entrant has no pending job applications, she has a higher probability of accepting a job offer, although the relative importance of this dimension is again low. This finding also reflects that mothers are generally less willing to move and are therefore more likely to accept a job when job availability becomes restricted in their geographical search radius (Abraham et al. 2013: 299; Abraham \& Nisic 2007).

The results regarding the relative importance of the dimensions are presented in Table 5. We propose that for the group under study, individual characteristics related to temporal flexibility are more important than monetary characteristics. We find that the relative importance of commuting time is the greatest of all dimensions, as it explains 38 percent of the total variance in the characteristics on the vignette level. However, the relative importance of wage loss is also high, with a share of 28 percent of the total variance explained by the vignette characteristics. In addition, the relative importance of the volume of work dimension is high; approximately 19 percent of the variance on the vignette level can be explained by this dimension. In contrast, the relative importance of the level of training dimension is comparatively low, explaining 8 percent of the total variance. Additionally, the flexibility dimension explains only 6 percent of the total variance, approximately equivalent to that explained by the training criterion. ${ }^{11}$ The temporal components of a job, namely, commuting time and volume of work, were indeed relevant for the group under study, although monetary job characteristics are also important. In contrast, the level of training, a

\footnotetext{
${ }^{11}$ Because the dimensions concerning job characteristics have the same number of levels, they can be compared with one another.
} 
characteristic that can be linked only indirectly to monetary compensation and the flexibility dimension seem less relevant.

Table 5 Relative importance of the dimensions

\begin{tabular}{lll}
\hline Variable & Variance explained & $\begin{array}{l}\text { Significance level of } \\
\text { partial correlations }\end{array}$ \\
\hline wage: 10 per cent less & & 0.000 \\
wage: 30 per cent less & 0.28 & 0.000 \\
training: slightly over qualified & & 0.000 \\
$\begin{array}{l}\text { training: clearly over qualified } \\
\text { working hours: agreed upon } \quad \text { with }\end{array}$ & 0.08 & 0.001 \\
$\begin{array}{l}\text { supervisor } \\
\text { working hours: fixed }\end{array}$ & 0.06 & 0.109 \\
$\begin{array}{l}\text { volume of work: more than planned } \\
\text { volume of work: less than planned }\end{array}$ & 0.19 & 0.000 \\
commuting time: 30 minutes & & 0.000 \\
commuting time: 45 minutes & 0.38 & 0.000 \\
search effort: just started & 0.00 & 0.000 \\
situation: no open applications left & 0.00 & 0.000 \\
\hline total variance explained & 0.24 & 0.445 \\
\hline
\end{tabular}

Finally, we address whether there are differences among women with different characteristics. Foremost, we assume that whether the woman is under pressure to find a job (e.g., because she is registered as unemployed or because the overall household income is low) is important. We therefore estimate two separate models, one for women not under pressure (Model 3) and another for women under pressure (Model 4), and tested whether the coefficients differ significantly. ${ }^{12}$ In both models, all job characteristics are significant with one exception: working hours agreed upon with the supervisor (as opposed to flexible working hours) do not reduce the acceptance probability any more than in the full model. This finding is difficult to interpret but ultimately can be attributed to the smaller sample sizes.

\footnotetext{
${ }^{12}$ We also estimated an interaction model including interactions with pressure. The results are similar and available upon request.
} 
Table 6 Random intercept models sample split for "under pressure to find a job"

\begin{tabular}{|c|c|c|c|}
\hline Dependent variable vignette judgment & $\begin{array}{c}\text { Model } 3 \\
\text { Not under } \\
\text { pressure }\end{array}$ & $\begin{array}{c}\text { Model } 4 \\
\text { Under } \\
\text { pressure }\end{array}$ & $\begin{array}{l}\text { wald-test } \\
\text { (p-values) }\end{array}$ \\
\hline
\end{tabular}

(0-100 per cent)

vignette level variables

wage: ref. according to previous job

wage: 10 per cent less

$\begin{array}{ccc}-6.68^{* * *} & -4.10^{* * *} & 0.000 \\ (1.17) & (1.04) & \\ -19.22^{* * *} & -18.14^{* * *} & 0.000 \\ (1.16) & (1.04) & \\ & & \\ -3.05^{* *} & -3.53^{* * *} & 0.032 \\ (1.16) & (1.04) & \\ -10.87^{* * *} & -6.825^{* * *} & 0.000 \\ (1.16) & (1.10) & \end{array}$

wage: 30 per cent less

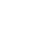

training: ref. according to training/abilities

training: slightly over qualified

training: clearly over qualified

(1.16)

working hours: ref. flexible

working hours: agreed upon with supervisor

$-1.47$

(1.16)

working hours: fixed

$-9.99^{* *}$

volume of work: ref. according to wishes

volume of work: more than planned

(1.10)

0.747

(1.04)

$-7.48^{* * *}$

0.000

$-17.22^{* * *}$

(1.17)

volume of work: less than planned

$-6.71^{* * *}$

(1.16)

(1.04)

$-9.22^{* * *}$

(1.16)

$-25.53^{* * *}$

(1.16)

$-13.10^{* * *}$

(1.04)

$-6.69^{* * *}$

(1.04)

commuting time: ref. 15 minutes

commuting time: 30 minutes

$\begin{array}{ll}-6.089^{* * *} & 0.000 \\ (1.05) & \\ -19.78^{* * *} & 0.000 \\ (1.03) & \end{array}$

search effort: ref. already searching for some time search effort: just started

$-1.85^{*}$

0.35

0.024

situation: ref. some applications left

(0.94)

$(0.84)$

situation: no open applications left

$2.77^{*}$

(0.95)

1.59

$(0.84)$

individual level variables

tertiary education ref. no

1.84

5.00

(2.43)

(2.65)

cohort 1 ref. cohort 2

2.40

3.66

(2.46)

(2.55)

partner fulltime employed ref. partner less than

$10.30^{*}$

$-0.46$

(5.08)

(2.65)

3.74

0.36

(3.61)

(3.67)

duration of interruption (in years)

$-0.07$

0.32

$(0.27)$

$(0.24)$

age (in years)

$-0.36$

0.06

(0.30)

(0.24)

living in new federal state ref. old federal states

3.33

0.71

(3.66)

(3.13)

participation group ref. comparison group

0.18

$-1.24$

(2.42)

$98.70^{* * *}$

(2.56)

$82.71^{* * *}$ 


\begin{tabular}{lcc} 
& $(12.13)$ & $(9.74)$ \\
\hline random intercept standard deviation & 15.49 & 17.56 \\
level 1 residual standard deviation & 19.86 & 19.44 \\
rho & 0.378 & 0.449 \\
chi2 & 1384.54 & 821.19 \\
individuals & 222 & 175 \\
observations & 2200 & 1725 \\
\hline
\end{tabular}

Random intercept models; standard errors in parentheses

${ }^{*} p<0.05,{ }^{* *} p<0.01,{ }^{* * *} p<0.001$, two-tailed tests

In addition, given that women under pressure have a significantly higher probability of accepting a job offer in the full model, we can conclude from Models 3 and 4 that the reduction in acceptance probability resulting from several vignette characteristics is less for women under pressure than for women not under pressure. For example, a 45-minute commute compared with a 15-minute commute decreases the likelihood of accepting a job offer by 25 percentage points for women who are under pressure to find a job. Conversely, a 45-minute commute decreases the acceptance probability by only 19 percentage points for women not under pressure. This difference is highly significant. Significant but less pronounced differences can also be found for a 30-minute commute compared with a 15 -minute commute. When examining wage reductions, we arrive at a similar conclusion. Wage reductions are significantly less important for women under pressure. For women under pressure, a 10 percent wage decrease lowers the acceptance probability by 4 percentage points, while a 30 percent decrease lowers the acceptance probability by 18 percentage points. In contrast, for women not under pressure, these numbers are 7 percentage points lower for a 10 percent wage decrease and 19 percentage points lower for a 30 percent wage decrease. In Table 3 , both wage decrease and commuting time are shown to be relatively important compared to the other characteristics. Furthermore, working more than planned is more relevant for women not under pressure; it decreases the acceptance probability by 17 percentage points compared to 14 percent for women under pressure. The difference between the coefficients is again highly significant. However, the effects of the other characteristics are less pronounced and/or not significant.

In summary, these results partially support hypothesis 7; at least some of the job characteristics are less important for women under pressure than for those not under pressure. Additionally, in Model 3 , the search phase and search situation are significant; this result is in contrast to the finding for Model 4 for women under pressure. 
Additionally, we tested for heterogeneity between other individual characteristics, such as the level of training or the presence of a child under six or a male earner in the household. Interactions between the vignette dimensions and the individual characteristics were also considered. We did not find significant interactions. Additional robustness checks examining different sub-groups, such as women living in the old and new federal states, women who belong to the participant or control group and women from the earlier and later wave, reveal some differences between the subgroups. However, these differences are not substantially meaningful because the magnitude and relative importance of the dimensions remain similar. Furthermore, methodological issues become relevant such as testing for the existence of satisficing strategies. Our results indicate that within the 10 judgements of each respondent sufficient variation exists. ${ }^{13}$

\section{CONCLUSIONS AND DISCUSSION}

This paper sheds light on the circumstances under which women return to the labor market after a family-related employment interruption. More precisely, we focus on job characteristics that influence the re-entry decision. From a theoretical perspective, we test implications of CWD theory (Rosen 1986; England 1992). CWD theory assumes that individuals trade wages for preferred job characteristics. The ambiguous results of previous research may be caused by the fact that it included women who are not really forced to make this trade-off and that it neglected the role of job opportunities that are not realized.

We contribute to the literature by using a factorial survey that can overcome these problems. We concentrate on mothers who interrupted employment for more than a year and thus had to search for a new job that could be combined with raising a young child. Our design allows us to derive direct conclusions about the exchangeability of job dimensions due to the statistical properties of the uncorrelated vignette dimensions of factorial surveys. The results of this study show that in addition to financial compensation, the characteristics of the situation in the prospective job are also important in shaping the re-entry decision. Beyond commuting time, wage losses play the most important role among all the characteristics we examined in our survey. Additionally, characteristics that influence a mother's temporal flexibility, such as working hours, are more relevant than characteristics related to job content. However, one has to bear in mind that the group under study - married mothers in their forties with lost ties to the labor market - is a special group.

\footnotetext{
13 The results are available upon request.
} 
The lack of importance of the level of over-qualification dimension may have been observed because mothers tend to search for jobs that are less demanding. This result is consistent with Gary Becker's (1993) assumption that the priorities of married women may shift from work to the family sphere. The results with regard to the flexibility dimension can be linked to planning security. If the working hours fit a mother's schedule, it does not matter whether those hours are fixed, negotiable (with the supervisor) or flexible. Indirectly, this result means that the mother probably assumes that the fixed working hours fit into her schedule.

We also find evidence that women under pressure have a different acceptance probability than women not under pressure. For other types of heterogeneity, little evidence is found. The characteristics of the search process itself were less relevant for the group under study (long-time inactive mothers) than were other variables, such as how long the mothers had already been searching and whether they still had open applications.

Using a factorial survey provides a different method for assessing the relevance of certain job characteristics. Admittedly, the results are limited to a comparison of the characteristics under study, but they nevertheless provide a fruitful starting point from which this question can be addressed in more detail. The hypotheses could also be tested under different situations, e.g., with unemployment benefit recipients in Germany for whom eventual wage losses are less relevant. This suggestion indicates the limitations of the study: no gold standard is available, and it is not possible to compare the results from the women under study with the results from a larger population survey with a broader target group, such as unemployed fathers or unemployed persons in general. However, the comparison of mothers under pressure and those not under pressure allows one to reasonably assume that similar mechanisms might be at work for those not studied. The magnitude of the effects, however, could be different because the marginal worker might have different preferences when different groups are studied. Additionally, the selected job characteristics should be regarded as exemplary characteristics. Presumably, other characteristics are also important. Another limitation is that all re-entrants receive the same number of job offers, which of course is not the reality. However, the factorial survey design with its fictive character also possesses an advantage: it avoids the selection problems often connected with realized versus unrealized decisions (Abraham \& Nisic 2012).

This research also has practical implications. The findings emphasize that monetary compensation is not the only important factor; jobs must also be family-friendly to attract future workforce 
potential. The results show that the prospective female re-entrants in our study were not willing to accept some jobs at any price. Specifically, they were not willing to accept a longer commuting time, perhaps because of their family obligations. According to our research results, jobs that allow for temporal flexibility are especially desirable. Thus, to support mothers, family and employment politicians, organizations and employers must continue to develop flexible working arrangements that better facilitate reconciliation of work and family.

\section{REFERENCES}

Abendroth, Anja-Kristin, Matt L. Huffman, and Judith Treas. 2014. "The Parity Penalty in Life Course Perspective: Motherhood and Occupational Status in 13 European Countries." American Sociological Review 79(5):993-1014.

Abraham, Martin, Katrin Auspurg, Sebastian Bähr, Corinna Frodermann, Stefanie Gundert, and Thomas Hinz. 2013. "Unemployment and Willingness to Accept Job Offers: Results of a Factorial Survey Experiment.” Journal for Labour Market Research 46(4):283-305.

Abraham, Martin and Natascha Nisic. 2007. "Regionale Bindung, räumliche Mobilität und Arbeitsmarkt - Analysen für die Schweiz und Deutschland." Schweizer Zeitschrift für Soziologie 33: 69-87.

Abraham, Martin and Natascha Nisic. 2012. “A Simple Mobility Game for Couples' Migration Decisions and Some Quasi-Experimental Evidence.” Rationality \& Society 24(2) 168-197.

Aisenbrey, Silke, Marie Evertsson, and Daniela Grunow. 2009. "Is There a Career Penalty for Mothers' Time Out? A Comparison of Germany, Sweden and the United States." Social Forces 88(2): 573-606.

Amuedo-Dorantes, Catalina and Jean Kimmel. 2008. New Evidence on the Motherhood Wage Gap. IZA Discussion Paper 3662. Bonn: Institute for the Study of Labor.

Auspurg, Katrin and Stefanie Gundert. 2015. "Precarious Employment and Bargaining Power. Results of a Factorial Survey Analysis." Zeitschrift für Soziologie 44(2):99-117.

Auspurg, Katrin, and Thomas Hinz. 2015. Factorial survey experiments. Thousand Oaks, CA: Sage (Quantitative Applications in the Social Sciences).

Bähr, Sebastian and Martin Abraham. 2016. "The Role of Social Capital in the Job-Related Regional Mobility Decisions of Unemployed Individuals." Social Networks 46:44-59. 
Beblo, Miriam, Stefan Bender and Elke Wolf. 2009. "Establishment-Level Wage Effects of Entering Motherhood.” Oxford Economic Papers 61(suppl. 1):i11-i34.

Becker, Gary S. 1991. “A Treatise on the Family. Enlarged Edition.” Cambridge, MA: Harvard University Press.

Becker, Gary S. 1993. Human Capital. A Theoretical and Empirical Analysis, with Special Reference to Education. Third Edition. Chicago: University of Chicago Press.

Berk, Richard. A. 2004. Regression Analysis. A Constructive Critique. London: Sage.

Boyle, Paul, Thomas Cooke, Keith Halfacree, and Darren Smith. 2003. "The Effect of LongDistance Family Migration and Motherhood on Partnered Women's Labour--Market Activity Rates in Great Britain and the USA.” Environment and Planning A 35(12):2097-2114.

Bring, Johan. 1994. "How to Standardize Regression Coefficients." The American Statistician 48(3): 209-213.

Budig, Michelle J. and Paula England. 2001. "The Wage Penalty for Motherhood." American Sociological Review 66(2):204-225.

Budig, Michelle J. and Melissa J. Hodges. 2010. "Differences in Disadvantages: Variation in the Motherhood Penalty across White Women's Earnings Distribution.” American Sociological Review 75(5): 705-728.

Budig, Michelle J., Joya Misra, and Irene Boeckmann. 2016. "Work-Family Policy Trade-Offs for Mothers? Unpacking the Cross-National Variation in Motherhood Earnings Penalties." Work and Occupations 43(2):119-177.

Cohany, Sharon R. and Emy Sok. 2007. "Trends in Labor Force Participation of Married Mothers of Infants." Monthly Labor Review 130: 9-16.

Correll, Shelley. J., Stephen Benard, and In Paik. 2007. “Getting a Job: Is There a Motherhood Penalty?" American Journal of Sociology 112(5):1297-1339.

Devine, Theresa J. and Nicolas M. Kiefer. 1991. Empirical Labor Economics. Oxford: Oxford University Press.

Diener, Katharina, Susanne Götz, Franziska Schreyer, and Gesine Stephan. 2013. „Beruflicher Wiedereinstieg von Frauen nach familienbedingter Erwerbsunterbrechung: Befunde der Evaluation des ESF-Programms "Perspektive Wiedereinstieg" des Bundesministeriums für Familie, Senioren, Frauen und Jugend“ IAB-Forschungsbericht, 09/2013, Nuremberg. 
Drasch, Katrin. 2013. "Do Changing Institutional Settings Matter? Educational Attainment and Family Related Employment Interruptions in Germany." European Sociological Review 29(5):49-63.

Dülmer, Herrmann. 2007. "Experimental Plans in Factorial Surveys: Random or Quota Design?" Sociological Methods \& Research 35(3):382-409.

Dülmer, Herrmann. 2016. "The Factorial Survey: Design Selection and its Impact on Reliability and Internal Validity." Sociological Methods \& Research 45(2):304-347.

Duncan, Greg J. and Bertil Holmlund. 1983. "Was Adam Smith Right After All? Another Test of the Theory of Compensating Wage Differentials." Journal of Labor Economics 1(4): 366-379. England, Paula. 1992. Comparable Worth: Theories and Evidence. New York: Aldine de Gruyter.

England, Paula, Jonathan Bearak, Michelle J. Budig, and Melissaa H. Hodges. 2016. "Do Highly Paid, Highly Skilled Women Experience the Largest Motherhood Penalty?" American Sociological Review 81(6): 1161-1189.

Felfe, Christina. 2009. “The Willingness to Pay for Job Amenities: Evidence from Mothers' Return to Work." ILR Review 65(2):427-454.

Felfe, Christina. 2012. “The Motherhood Wage Gap: What about Job Amenities?" Labour Economics 19(1): 59-67.

Filer, Randall. 1985. "Male-Female Wage Differences: The Importance of Compensating Differentials." Industrial and Labor Relations Review 38(3):426-437.

Flabbi, Luca and Andrea Moro. 2012. "The Effects of Job Flexibility on Female Labor Market Outcomes: Estimates From a Search and Bargaining Model.” Journal of Econometrics 168:8195.

Fuller, Sylvia. 2008. "Job Mobility and Wage Trajectories for Men and Women in the United States." American Sociological Review 73:158-183.

Gangl, Markus and Andrea Ziefle. 2009. “Motherhood, Labor Force Behavior, and Women's Careers: An Empirical Assessment of the Wage Penalty for Motherhood in Britain, Germany, and the United States.” Demography 46(2):341-369.

Glass, Jennifer and Valerie Camarigg. 1992. "Gender, Parenthood, and Job-Family Compatibility." American Journal of Sociology 98(1): 131-151.

Glauber, Rebecca. 2012. “Women’s Work and Working Conditions: Are Mothers Compensated for Lost Wages?” Work and Occupations 39(2):115-138. 
Glomb, Theresa M., John D. Kammeyer-Mueller, and Maria Rotundo. 2004. Emotional Labor Demands and Compensating Wage Differentials." Journal of Applied Psychology 89(4):700714.

Gough, Margaret and Mary Noonan. 2013. "A Review of the Motherhood Wage Penalty in the United States." Sociology Compass 7(4):328-342.

Groot, Wim. 1990. "Heterogeneous Jobs and Re-employment Probabilities." Oxford Bulletin of Economics and Statistics 52(3):253-267.

Hanel, Barbara, Regina T. Riphahn. 2012. "The Employment of Mothers. Recent Developments and Their Determinants in East and West Germany." Journal of Economics and Statistics 232(2): 145-173.

Kahneman, Daniel, Paul Slovic, and Amos Tversky (Eds.). 1982. Judgment under Uncertainty: Heuristics and Bases. Cambridge: Cambridge University Press.

Kahneman, Daniel and Amos Tversky. 1979. "Prospect Theory: An Analysis of Decision under Risk." Econometrica 47:263-291.

Kilbourne, Barbara Stanek, Paula England, George Farkas, Kurt Beron and Dorothea Weir. 1994. „Returns to Skill, Compensating Differentials, and Gender Bias: Effects of Occupational Characteristics on the Wages of White Women and Men." American Journal of Sociology 100(3): 689-719.

Kuhfeld, Warren F. 2010. Marketing Research Methods in SAS. Experimental Design, Choice, Conjoint, and Graphical Techniques. Cary: SAS Institute.

Kuhfeld, Warren F., Randall D. Tobias, and Mark Garratt. 1994. "Efficient Experimental Design with Marketing Research Applications.” Journal of Marketing Research 31(4): 545-557.

Kunze, Astrid. 2002. "The Timing of Careers and Human Capital Depreciation." IZA Discussion Paper 509. Bonn: Institute for the Study of Labor.

Levanon, Asaf, Paula England, and Paul Allison. 2009. "Occupational Feminization and Pay: Assessing Causal Dynamics using 1950-2000 U.S. Census Data." Social Forces 88(2):865891.

McCrate, Elaine. 2005. "Flexible Hours, Workplace Authority, and Compensating Wage Differentials in the US." Feminist Economics 11(1):11-39.

Mincer, Jacob. 1974. Schooling, Experience, and Earnings. New York: National Bureau of Economic Research. 
Mincer, Jacob and Haim Ofek. 1982. "Interrupted Work Careers: Depreciation and Restoration of Human Capital." The Journal of Human Resources 17(1):3-24.

Rabe-Hesketh, Sophia and Anders Skrondal. 2012. "Multilevel and longitudinal modeling Using Stata. Volume I: Continuous Responses.” Third Edition. College Station, TX: Stata Press.

Rogerson, Richard, Robert Shimer, and Randall Wright. 2005. "Search-Theoretic Models of the Labor Market: A Survey.” Journal of Economic Literature 43(4):959-988.

Rosen, Sherwin. 1986. The Theory of Equalizing Differences. pp. 641-69 in Handbook of Labor Economics, edited by Orley C. Ashenfelter, and Richard Layard. Amsterdam: Elsevier.

Shihadeh, Edward S. 1991. "The Prevalence of Husband-Centered Migration: Employment Consequences for Married Mothers.” Journal of Marriage and Family 53:432-444.

Steiner, Peter M. and Christiane Atzmüller. 2006. "Experimentelle Vignettendesigns in faktoriellen Surveys.“ Kölner Zeitschrift für Soziologie und Sozialpsychologie, 58(1):117-146.

Villanueva, Ernesto. 2007. Estimating Compensating Wage Differentials using Voluntary Job Changes: Evidence from Germany." ILR Review 60(4):544-561.

Wallander, Lisa. 2009. 25 years of Factorial Surveys in Sociology: A Review." Social Science Research 38(3):505-520.

Weeden, Kim A. 2005. Is there a Flexiglass Ceiling? Flexible Work Arrangements and Wages in the United States." Social Science Research 34(2):454-482.

Wooldridge, Jeffrey M. 2002. Econometric Analysis of Cross-section and Panel Data. Second Edition. Cambridge, MA: MIT Press. 